\title{
Risk behaviors among sexual partners of African American and Latino online social network - using men who have sex with men
}

\author{
Renee Garett ${ }^{1}$, Sean Young ${ }^{2}$ \\ ${ }^{1}$ ElevateU, Los Angeles, California, United States of America \\ ${ }^{2}$ Department of Family Medicine, University of California, Los Angeles, California, United States of America
}

\begin{abstract}
Introduction: Aim of the study was to clarify the basic demographic characteristics, sexual risk behaviors, and online social network use of the sexual partners of African American and Latino men who have sex with men (MSM) to inform interventions. African American and Latino MSM are increasingly using online social networks to meet sexual partners. Online social network interventions are being designed to increase HIV prevention among these populations with the hope that the interventions will spread throughout the social networks to also reduce risk among sexual partners. However, little is known about the sexual partners of African American and Latino MSM or how these partners might impact HIV risk.

Material and methods: This study was a cross-sectional survey study that took place in fall of 2012. Forty-four participants were recruited via referrals from a previous study with high-risk MSM. Participants were invited to contact their current, former, or potential sexual partners on Facebook. Sexual behavior and online social network usage data were collected.

Results: The participants had a mean age of 31.8 years old. More than $50 \%$ of partners had not been tested for HIV in the past 12 months, nearly $30 \%$ were previously diagnosed with a sexually transmitted disease, and $15 \%$ had used drugs while having sex. $36 \%$ of the participants had gone online to meet new sexual partners.

Conclussion: Results suggest that sex partners of African American and Latino MSM are engaging in behaviors (drug use and lack of testing for STDs) that are associated with an increased risk of HIV/ AIDS. Additional studies should elucidate the characteristics of interconnected sexual networks that facilitate rapid transmission of HIV as well as create tailored and culturally appropriate interventions for minority men who have sex with men.
\end{abstract}

HIV AIDS Rev 2018; 17, 2: 117-121 DOI: https://doi.org/10.5114/hivar.2018.76372

Key words: HIV/AIDS, men who have sex with men, African American/Black and Latino, social media, sexual partners.

Address for correspondence: Sean D. Young, $\mathrm{PhD}$, MS, Department of Family Medicine, University of California, Los Angeles, 10880 Wilshire Blvd, Suite 1800, Los Angeles, CA 90024, USA, phone: +001 310-794-8530, fax: +001 310-794-6097, e-mail: sdyoung@mednet.ucla.edu
Article history:

Received: 27.03.2017

Received in revised form: 16.11 .2017

Accepted: 10.01.2018

Available online: 21.05.2018
International Journal of HIV-Related Problems

HIV \& AIDS

R e v i e w 


\section{Introduction}

HIV continues to be significant public health issue, especially among men who have sex with men (MSM) [1]. More than half of newly diagnosed HIV cases in 2010 could be attributed to male-to-male transmission [1]. Moreover, HIV rates among African American and Latino MSM are significantly higher than MSM of other racial or ethnic groups [2-4]. Los Angeles County currently has the second highest number of HIV cases in the United States, and similar to the national epidemic, African American and Latino MSM have the highest rates of HIV [5]. African American and Latino MSM are increasingly using social media to seek new sexual partners to avoid high levels of stigma, and this use of online social networks has been associated with increased sexual risk behaviors [6]. For example, Young et al. [6] found that among MSM, meeting sexual partners online was associated with an increased likelihood of having sex in exchange for food, drugs, or shelter. In addition, MSM were found to have higher numbers of both new sexual partners and male sexual partners in the past three months [6].

Although most studies focus on individual risk factors (e.g., number of sexual partners, condom use) [1], HIV transmission is a social phenomenon and the social context of risk behaviors should be considered [3, 4]. For example, research with MSM suggests a link between sexually transmitted infections and affiliation with a gay-centric social network [7]. Among minority populations, such as African American men, this effect is even stronger [8, 9]. Studies have also used social networks as a way to monitor and track the spread of sexually transmitted disease outbreaks $[10,11]$. Understanding the role of social networks in HIV transmission has been an effective tool in reducing sexual risk behaviors [12-14], demonstrating the importance of studying sexual networks of individuals at risk for HIV. However, it is unknown whether and how interventions that make use of social networks diffuse to other sex partners.

Given the increased risk of HIV among African American and Latino MSM, it is particularly important to examine attitudes and behaviors of sexual partners of individuals from these populations in order to design effective interventions. To study the implementation science behind social network-based HIV interventions and best methods for delivering them, research is first needed to understand the sexual partners of participants in online social network interventions in order to create more effective interventions that could diffuse to them throughout social networks.

This study seeks to describe the demographic characteristics, sexual risk behaviors, and online social network use among former, current, and potential sexual partners of African American and Latino online social network - using MSM who were part of an HIV intervention.

\section{Material and methods}

This study took place during October and November of 2012. The study protocol was approved by the University of California, Los Angeles (UCLA) Institutional Review Board (IRB). Forty-four participants were recruited via referrals from a previous intervention study among high-risk (primarily African American and Latino) MSM [15, 16]. Participants were contacted one year after they had completed the Harnessing Online Peer Education (HOPE) intervention, and invited to contact their current, former, or potential sexual partners on Facebook who would be interested in filling out a survey and receive a free in-home rapid HIV test kit. These sexual partners were told to contact the study team by e-mail if they were interested in participating in the study. Participants who made contact were sent an e-mail with study information and an online consent form, along with a brief series of screening questions. Facebook profile information was used to verify that participants were linked to a HOPE participant.

HOPE participants were paid US $\$ 10$ for each participant (up to 5 participants each) who completed the survey. The partners of HOPE participants received US\$30 in online gift cards for completing the 92-item survey. We asked the participants to only contact their first-degree (Facebooklinked) current or former sexual partners who were 18 years of age or older.

\section{Measures}

\section{Demographics}

We collected data on the participants' age, gender, race/ ethnicity, primary language (English or Spanish), highest education attainment, sexual orientation, and partnership status. Participants were also asked if they had talked to others about sexual health (e.g., condom use and HIV testing) in the past three months.

\section{Sexual risk behavior and Internet use}

Participants were asked if they had been professionally diagnosed with a sexually transmitted disease (STD), had been tested for HIV in the past 12 months, or had had sex while they were high or using drugs in the past three months. In addition, to assess online social network use, participants were asked to indicate the amount of time daily they spent on online social networks and if they had gone online to meet new sexual partners. All analyses were conducted with STATA SE, version 12.0 (StataCorp, College Station, TX, USA).

\section{Results}

\section{Basic demographics}

Participants had a mean age of 31.8 years $(S D=6.74)$ and were predominantly male $(81.8 \%)$, gay $(68.2 \%)$, and currently single/never married (47.7\%). More than $50 \%$ 
Table 1. Demographic characteristics of partners of HOPE study participants $(n=44)$

\begin{tabular}{|c|c|c|}
\hline \multicolumn{3}{|l|}{ Characteristics } \\
\hline \multirow[t]{2}{*}{ Mean age (standard deviation) } & \multicolumn{2}{|c|}{$31.8(6.74)$} \\
\hline & $n$ & $\%$ \\
\hline \multicolumn{3}{|l|}{ Gender } \\
\hline Male & 36 & 81.8 \\
\hline Female & 8 & 18.2 \\
\hline \multicolumn{3}{|l|}{ Education } \\
\hline High school or less & 11 & 25.0 \\
\hline GED or associate's degree & 8 & 18.2 \\
\hline Bachelor's degree & 16 & 36.4 \\
\hline Graduate school & 8 & 18.2 \\
\hline Unreported & 1 & 2.2 \\
\hline \multicolumn{3}{|l|}{ Race/ethnicity } \\
\hline White & 14 & 31.8 \\
\hline African American & 4 & 9.1 \\
\hline Asian or Pacific Islander & 6 & 13.6 \\
\hline Latino & 20 & 45.5 \\
\hline \multicolumn{3}{|l|}{ Is Spanish your primary language? } \\
\hline Yes & 2 & 4.5 \\
\hline \multicolumn{3}{|l|}{ Sexual orientation } \\
\hline Gay & 30 & 68.2 \\
\hline Bisexual & 1 & 2.3 \\
\hline Heterosexual & 11 & 25.0 \\
\hline Questioning & 2 & 4.5 \\
\hline \multicolumn{3}{|l|}{ Current partnership status } \\
\hline Single (never married) & 21 & 47.7 \\
\hline Legally married/domestic partnership & 10 & 22.7 \\
\hline Partnered & 9 & 20.5 \\
\hline Divorced/widowed/separated & 4 & 9.1 \\
\hline
\end{tabular}

of the participants had a bachelor's or higher degree (56.8\%). Although roughly half of the participants self-identified as Latino (45.5\%), only two individuals identified Spanish as their primary language (4.5\%) (Table 1).

\section{Sexual risk behavior and online social network use}

More than a quarter of participants had been diagnosed by a health professional as having an STD (27.3\%). The majority of participants had not had sex under the influence of drugs (84.1\%), and about half of the participants had been tested for HIV in the past 12 months (45.5\%). 95.4\% of participants went online for one hour or more each, but only $36.4 \%$ of the participants used online social networks to meet new sexual partners. Almost all participants (95.5\%) had talked to others about sexual health (e.g., condom use, HIV testing) (Table 2).
Table 2. Sexual risk behaviors and online social network use for the partners of HOPE study participants $(n=44)$

\begin{tabular}{|c|c|c|}
\hline Characteristics & $n$ & $\%$ \\
\hline \multicolumn{3}{|l|}{$\begin{array}{l}\text { Have you ever been diagnosed by a health } \\
\text { professional (doctor, nurse, etc.) as having } \\
\text { a sexually transmitted disease (STD) } \\
\text { such as chlamydia, syphilis, gonorrhea, } \\
\text { HPV, or herpes? }\end{array}$} \\
\hline Yes & 12 & 27.3 \\
\hline \multicolumn{3}{|l|}{$\begin{array}{l}\text { Have you been tested for HIV in the last } \\
12 \text { months? }\end{array}$} \\
\hline Yes & 20 & 45.5 \\
\hline \multicolumn{3}{|l|}{$\begin{array}{l}\text { In the past } 3 \text { months, how often were you } \\
\text { high or using drugs while you were having } \\
\text { sex? }\end{array}$} \\
\hline None of the time & 37 & 84.1 \\
\hline Less than half & 6 & 13.6 \\
\hline About half & 1 & 2.3 \\
\hline \multicolumn{3}{|l|}{$\begin{array}{l}\text { In the past three months, how much time } \\
\text { do you spend online each day? }\end{array}$} \\
\hline Less than 1 hour & 2 & 4.6 \\
\hline $1-3$ hours & 18 & 40.9 \\
\hline $3+$ hours & 24 & 54.5 \\
\hline \multicolumn{3}{|l|}{$\begin{array}{l}\text { In the past } 3 \text { months, have you used } \\
\text { online social networks to meet new sexual } \\
\text { partners? }\end{array}$} \\
\hline Yes & 16 & 36.4 \\
\hline \multicolumn{3}{|l|}{$\begin{array}{l}\text { In the past } 3 \text { months, have you talked to } \\
\text { others about sexual health on online social } \\
\text { networks (using condoms, getting an HIV } \\
\text { test, and etc.)? }\end{array}$} \\
\hline Yes & 42 & 95.5 \\
\hline
\end{tabular}

\section{Discussion}

To the best of our knowledge, this is the first study that describes the basic demographics, online social network use, and sexual risk behaviors of sexual partners of African American and Latino social network-using MSM. Results help to provide support for how social network interventions among minority MSM can be developed to additional target diffusion to their sexual partners. Although nearly all participants in this study talked to other people about sexual health, more than half of the participants had not been tested in the past 12 months (54.5\%). This duration exceeds the CDC recommendation for HIV testing: high-risk populations, such as African American and Latino MSM, should be routinely tested every three to six months [16]. This is troubling, because $27.3 \%$ of participants indicated that they had been diagnosed with an STD (e.g., syphilis, herpes, chlamydia, gonorrhea), and more than $15 \%$ had been high or used drugs while having sex. Both of these statistics are associated with increased risk 
of HIV/AIDS [17, 18]. Future intervention programs should focus on helping individuals realize the urgent need of being tested, because being aware of one's HIV infection reduces the likelihood of transmitting the virus [19]. The high number of individuals who had not been tested might be explained by the recruitment methodology of using Facebook referrals. Due to ethical limitations, we were unable to directly reach out to the original HOPE participant's friends on Facebook. Participants in the study were current or former and potential sexual partners referred by participants of the HOPE study. Although we cannot ascertain if the recruiters and their sexual partners had met on online social networks, more than a third of the participants (36.4\%) had used online social networks to meet new sexual partners in the past three months. In general, those who rely heavily on the Internet to find sexual partners are less likely to be tested for HIV at traditional venues. This is because they are usually less associated with the gay community and have less exposure to culturally sensitive HIV prevention programs and services [20-22].

A significant number of participants in the study identified as Latinos (45.5\%). This finding indicated that African American and Latino MSM often have sex with individuals from the same ethnic/cultural background and from the same high-risk communities. Many studies have found that African American MSM tend to have small and interconnected sexual networks, and that they are significantly more likely to have sexual partners of the same race [4]. Given the high rates of HIV among African American MSM, these small and interconnected sexual networks facilitate rapid transmission of HIV.

This study has several limitations. First, we had a relatively small sample size due to the nature of our data collection. Repeating this study and conducting other will be valuable in order to truly identify the characteristics and demographics of the HOPE participants' sexual partners. For example, increasing the sample size would allow exploration of moderating variables such as sex and race/ ethnicity. The small sample size was partially due to recruiting partners through former HOPE participants. Although we had access to the data, ethical limitations prevented us from directly contacting the HOPE participants' Facebook connections. Another limitation is the self-reporting nature of surveys. Due to the personal content of the questions in this study, some participants may have not reported entirely truthfully, despite the assurance of anonymity.

Intervention studies of online communities and social networks have been conducted [16], but it is still unknown if these interventions are effecting the lifestyles of the participants' sexual partners as intended. Our study can help identify how sexual partners' behavior might change over time and therefore inform appropriate interventions to protect a high-risk population from contracting HIV. Results suggest that future interventions targeting African American and Latino MSM should also target their sexual partners, who are often from the same racial/ ethnic populations, and in need of a recent HIV test according to testing guidelines.

\section{Conclusions}

Based on the findings from this study, we see roughly $15 \%$ of our participants stated that they were high or using drugs while having sex, and the majority of our participants were not being tested for HIV at the recommended frequency. These are two behaviors that put an already high-risk population of African American and Latino MSM at an elevated risk for contracting HIV.

Community-level interventions that take into consideration sexual partners are important for high-risk populations. However, more studies are needed to further understand the social and sexual networks of high-risk African American and Latino online social network-using MSM. Additional studies will facilitate the development of tailored and culturally appropriate interventions.

\section{Funding}

The authors graciously acknowledge the National Institute of Mental Health (NIMH) for providing support for this project (K01 MH090884-01A1).

\section{Conflict of interest}

The authors declare no potential conflicts of interest with respect to the research, authorship, and/or publication of this article.

\section{References}

1. Centers for Disease Control and Prevention (CDC). HIV testing and risk behaviors among gay, bisexual, and other men who have sex with men - United States. MMWR Morb Mortal Wkly Rep 2013; 62: 958-962.

2. Maulsby C, Millett G, Lindsey K, et al. HIV among Black men who have sex with men (MSM) in the United States: a review of the literature. AIDS Behav 2014; 18: 10-25.

3. Hall HI, Byers RH, Ling Q, et al. Racial/ethnic and age disparities in HIV prevalence and disease progression among men who have sex with men in the United States. Am J Public Health 2007; 97: 1060-1066.

4. Millett GA, Peterson JL. Flores SA, et al. Comparisons of disparities and risks of HIV infection in black and other men who have sex with men in Canada, UK, and USA: a meta-analysis. Lancet 2012; 380: 341-348.

5. HIV Epidemiology Program Los Angeles County Department of Health Services, Special data run, Los Angeles County Department of Public Health, Los Angeles 2008.

6. Young SD, Szekeres G, Coates T. The relationship between online social networking and sexual risk behaviors among men who have sex with men (MSM). PLoS One 2013; 8: e62271.

7. Amirkhanian YA, Kelly JA, Takacs J, et al. HIV/STD prevalence, risk behavior, and substance use patterns and predictors in Russian and Hungarian sociocentric social networks of men who have sex with men. AIDS Educ Prev Off Publ Int Soc AIDS Educ 2009; 21: 266-279.

8. Amirkhanian YA. Social networks, sexual networks and HIV risk in men who have sex with men. Curr HIV/AIDS Rep 2014; 11: 81-92.

9. Mimiaga MJ, Reisner SL, Cranston K, et al. Sexual mixing patterns and partner characteristics of black MSM in Massachusetts at increased risk for HIV infection and transmission. J Urban Health Bull N. Y. Acad Med 2009; 86: 602-623. 
10. Young SD, Rivers C, Lewis B. Methods of using real-time social media technologies for detection and remote monitoring of HIV outcomes. Prev Med 2014; 63: 112-115.

11. Charles-Smith LE, Reynolds TL, Cameron MA, et al. Using Social Media for Actionable Disease Surveillance and Outbreak Management: A Systematic Literature Review. PLoOS One 2015; 10: e0139701.

12. Qiao S, Li X, Stanton B. Social Support and HIV-related Risk Behaviors: A Systematic Review of the Global Literature. AIDS Behav 2014; 18: 419-441.

13. Kimbrough LW, Fisher HE, Jones KT, et al. Accessing social networks with high rates of undiagnosed HIV infection: The social networks demonstration project. Am J Public Health 2009; 99: 1093-1099.

14. Young SD, Jaganath D. Online social networking for HIV education and prevention: a mixed-methods analysis. Sex Transm Dis 2013; 40: $162-167$.

15. Young SD, Cumberland WG, Lee SJ, et al. Social networking technologies as an emerging tool for HIV prevention: a cluster randomized trial. Ann Intern Med 2013; 159: 318-324.

16. TMUS. Campaigns Act Against AIDS, CDC (2014). Available from: https://www.cdc.gov/actagainstaids/campaigns/tmus/index. html (Accessed: 8.11.2017)

17. HIV/AIDS. NIH: National Institute of Allergy and Infectious Diseases (2009). https://www.niaid.nih.gov/diseases-conditions/hivaids (Accessed: 8 November 2017).

18. Morgan E, Skaathun B, Michaels S, et al.; UConnect Study Team. Marijuana Use as a Sex-Drug is Associated with HIV Risk Among Black MSM and Their Network. AIDS Behav 2016; 20: 600-607.

19. Marks G, Crepaz N, Janssen RS. Estimating sexual transmission of HIV from persons aware and unaware that they are infected with the virus in the USA. AIDS Lond Engl 2006; 20: 1447-1450.

20. Katz DA, Swanson F, Stekler JD. Why do men who have sex with men test for HIV infection? Results from a community-based testing program in Seattle. Sex Transm Dis 2013; 40: 724-728.

21. Sumartojo E, Lyles C, Choi K, et al.; City Study Team. Prevalence and correlates of HIV testing in a multi-site sample of young men who have sex with men. AIDS Care 2008; 20: 1-14.

22. Washington TA, Robles G, Malotte K. Factors associated with HIVtesting history among Black men who have sex with men (BMSM) in Los Angeles County. Behav Med 2013; 39: 52-59. 